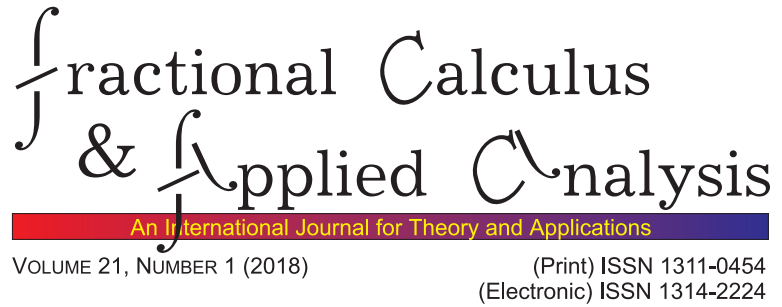

EDITORIAL

FCAA RELATED NEWS, EVENTS AND BOOKS

(FCAA-VOLUME 21-1-2018)

\title{
Virginia Kiryakova
}

Dear readers,

in the Editorial Notes we announce news for our journal, anniversaries, information on international meetings, events, new books, etc. related to the FCAA ("Fractional Calculus and Applied Analysis") areas. All these Notes are published online with free open access.

This special issue of the journal contains some 15 papers selected from the presentations at 8th International Conference TMSF 2017: "Transform Methods and Special Functions 2017", 27-31 August 2017, Sofia, Bulgaria, http://www.math.bas.bg/ tmsf/2017/.

Announces on the conference were published in previous journal's issues and a detailed report can be found in Editorial Note "FCAA Special Issue (FCAA-Volume 20-5-2017)", pp. 1056-1058, DOI: 10.1515/fca-2017-0055; see at https://www.degruyter.com/view/j/fca.2017.20.issue-5/ issue-files/fca.2017.20.issue-5.xml.

\section{Calendar of FC Related Meetings}

10th Workshop SDS 2018:

"Structural Dynamical Systems: Computational Aspects"

(12-15 June 2018, Capitolo (Monopoli) - Bari, Italy)

Website: https://sites.google.com/site/workshopsds2018

The workshop will take place at the Hotel Villaggio Porto Giardino in Capitolo-Monopoli (Italy). Monopoli is a seaside city and Capitolo is famous for its white sand beaches with crystal clear water in a walking distance from the hotel.

The aim of the workshop SDS is to bring together researchers from different areas (in particular Mathematics, Physics and Engineering) and give them the opportunity of discussing, in a friendly atmosphere, recent developments in computational and theoretical methods for Dynamical Systems and their applications.

(c) 2018 Diogenes Co., Sofia

pp. 1-9, DOI: 10.1515/fca-2018-0001

DE GRUYTER 
A special session devoted to "Fractional Order Systems" is planned. Prof. Kai Diethelm accepted to deliver the plenary talk introducing the session.

A selection of works presented during the workshop will be published on a special issue of the journal "Applied Numerical Mathematics".

Your participation to this workshop and the presentation of a contribution is highly welcome.

Deadlines: Abstract submission - 30 March 2018; Notification of acceptance - 20 April 2018; Early Registration - 30 April 2018; Late registration - 1 May 2018. Standard conference Fees (early registration) - EUR 200.

We hope to meet you during the SDS Workshop in Monopoli.

For further information you can contact me at the E-mail address:

roberto.garrappa@uniba.it or r.garrappa@gmail.com.

Best regards, Dr. Roberto Garrappa, University of Bari, Italy

ICFDA 2018: "International Conference on Fractional Differentiation and its Applications"

(16-18 July 2018, Amman, The Hashemite Kingdom of Jordan) Website:

http://conferences.ju.edu.jo/en/icfda2018/Home.aspx

See details in the previous Editorial Note, Volume 20, No 6 (2017), at https://www.degruyter.com/view/j/

fca.2017.20.issue-6/issue-files/fca.2017.20.issue-6.xml.

Reminder about Important Dates: - Submission of tutorials and special sessions proposals: Feb. 15, 2018; - Submission of regular and student papers: March 1, 2018; - Notification of acceptance: May 2, 2018; - Submission of camera-ready papers: May 25, 2018.

On behalf of Organizers, ICFDA 2018 General Chair:

Prof. Shaher Momani, Dean of Academic Research

The University of Jordan, Amman, Jordan

E-mail 1: icfda18@ju.edu.jo, E-mail 2: s.momani@ju.edu.jo

9th International Conference on Computational Methods, ICCM 2018 (6-10 August, 2018, Rome, Italy)

Website: http://www.sci-en-tech.com/ICCM/ index.php/ICCM2018/ICCM2018

The following Mini Symposium is organized: 


\section{MS-055: "Fractional Computational and Mathematical Models for Advanced Material Behavior"}

We would kindly invite you to contribute to our Mini Symposium. The abstract should be submitted electronically through the normal online procedure at:

http://www.sci-en-tech.com/ICCM/index.php/ICCM2018/ICCM2018.

Please remember that the Mini-Symposium is identified as 'MS-055' when submitting your abstract. The deadline for the abstract submission is March 30th, 2018.

For organization purposes, we would appreciate if you could please email us your abstract (or at least a tentative title with the list of authors) at your earliest convenience.

E-mail: francesco.pinnola@unisalento.it.

We look forward to seeing you in Rome next August. Yours sincerely, Dr. Massimiliano Zingales, University of Palermo, Italy

Dr. Giuseppe Failla, University of Reggio Calabria, Italy

Dr. Francesco Paolo Pinnola, University of Salento, Italy

NABVP 2018: International Conference

in Nonlinear Analysis and Boundary Value Problems 2018 (4-7 September, 2018, Santiago de Compostela, Spain)

Website: https://bvp2018.es/

The Group of Nonlinear Differential Equations at the University of Santiago de Compostela, Spain, is organizing this conference, to be held in honor of Prof. Juan J. Nieto, on occasion of his 60th birthday.

Prof. Nieto is a member of Editorial Board of the "FCAA" journal, some short CV details available at the above website.

The scientific program will consist of 4 plenary talks, 12 invited talks, and a number of contributed talks.

Dates, deadlines and fees: - The regular conference fee is EUR 250 for early registration until June 15, 2018 and EUR 300 afterwards. It includes the book of abstracts, coffee breaks, lunches and social program, for additional social events - see at the website; - Registration and abstract submission will be possible from March 15, 2018 on with Deadline - May 15, 2018; - Abstract acceptance - May 31, 2018.

Best regards, on behalf of Organizers, Chairman:

Prof. Alberto Cabada, Universidade de Santiago de Compostela, Spain;

E-mail: alberto.cabada@usc.es 


\section{9th International Workshop AMADE 2018: \\ "Analytical Methods of Analysis and Differential Equations" (10-12 September 2018, Minsk, Belarus \\ Website: http://amade.bsu.by/}

The Belarusian State University and the Institute of Mathematics of the Belarusian National Academy of Sciences together with Moscow State University organize this Workshop, dedicated to the memory of the brilliant mathematician and co-organizer of AMADE Conferences, Professor Anatoly Kilbas (1948 - 2010).

The Workshop keeps the tradition of previous conferences "Boundary Value Problems, Fractional Calculus and Special Functions" (1996), "Analytical Methods of Analysis and Differential Equations" (1999, 2001, 2003, 2006, 2009, 2011, 2012, 2015), held in Minsk, Belarus. The Workshop is organizing under the guidance of the International Society for Analysis, its Applications and Computation (ISAAC).

Arrival and departure days are September 10 and 14, 2018.

AMADE 2018 is organized in the workshop format: invited lectures of the well-known experts will be given and selected short reports will be presented.

The Topics of AMADE-2018: - 1. Integral Transforms and Special Functions; - 2. Differential Equations; - 3. Fractional Calculus; - 4. Real and Complex Analysis; - 5. Mathematical Methods in Economics; - 6. Modern Problems of Mechanics, Biomechanics and Nano-mechanics.

Would you like, please, to confirm your participation at AMADE-2018 and send us till May 1st, 2018: - names, affiliation, address, title of talk; one-page abstract in LaTeX. First announcement is available at the website. In May, 2018, Second Announcement will be spread.

Conference address: AMADE 2018 - Belarusian State University, Economics Faculty, Nezavisimosti Ave, 4, 220030 Minsk 30, Belarus;

E-mail: amade@bsu.by

On behalf of Organizers:

Prof. Sergei Rogosin, Belarusian State University 


\section{65th Anniversary of Dr. Sergei Rogosin}

Professor Sergei Rogosin was born in August, 11, 1952 in Arkhangelsk region of Russia. He was an active boy and had very inquiring mind. At school Sergei was interested in many subjects: mathematics, physics, history etc. He took part at the different competitions for schoolchildren. At 1969 Sergei finished school with a gold medal and entered the Mathematical Faculty of Belarusian State University in Minsk. Graduating from Belarusian State University (BSU) in 1974 he started to work at Syktyvkar State University. Since 1977 he is working at Belarusian State University and became Associate Professor there since 1990.

Sergei is one of the last post-graduate students of academician F.D. Gakhov. F.D. Gakhov noticed the interest in research of the young man and invited him to join scientific school formed at the Department of Functions Theory. Thus he obtained PhD at BSU. Later, Professor Rogosin has created his own research groups in Belarusian State University and leads a number of projects within the framework of State Research Programs and the Belarusian Fund for Fundamental Research. He is also a coordinator of European international scientific programs at the Belarusian State University.

Numerous international contacts promote the broadening of mathematical outlook of Rogosin. A scientific erudition of Rogosin is amazing. Representatives of many important mathematical editions ask him to review and to make abstracts of some books and papers. He is a member of the Editorial Board of the international journals: Fractional Calculus and Applied Analysis (Sofia, Bulgaria), Mathematical Modelling and Analysis (Vilnius, Lithuania), Analysis (München, Germany), Mathematics in Engineering, Science and Aerospace (Cambridge, UK), Siauliai Mathematical Seminar (Siauliai, Lithuania). He is a member of Board of ISAAC (International Society for Analysis, its Applications and Computation).

An important milestone of scientific life of Sergei is the organization of international conferences in Minsk. In 1996 professor Anatoly Kilbas brought an idea to hold a conference, dedicated to the memory of academician F.D. Gakhov. S. Rogosin became a scientific secretary of organizing committee. It was created a not big, but very active and cohesive group of organizers. The International conference "Boundary Value problems, Special Functions and Fraction Calculus" went off successfully. In 1999 due to advice of Prof. A.P. Prudnikov, the conference has got a new title "Analytic methods of Analysis and Differential Equations" (AMADE). Since that its subject area and circle of participants were extended. After this time the conferences AMADE were hold regularly (2001, 2003, 2006, 2009, 
2011, 2012, 2015). The forthcoming AMADE Conference (10-13 September, 2018) will be dedicated to 70th anniversary of A. Kilbas.

Sergei Rogosin is an editor of many books and an author of 3 monographs:

- Mityushev V.V., Rogosin S.V. Constructive Methods for Linear and Nonlinear Boundary Value Problems for Analytic Functions: Theory and Applications. Ser. Monographs and Surveys in Pure and Applied Mathematics, Vol. 108, Chapman \& Hall / CRC Press, Boca Raton - London New York - Washington, 1999; xii + 284 p.

- Rogosin S., Mainardi F. Legacy of A.Ya. Khintchine work in Probability Theory. Cambridge Scientific Publishers, Cottenham, 2011; xiv + 275 p.

- Gorenflo R., Kilbas A., Mainardi F., Rogosin S. Mittag-Leffler Functions: Related Topics and Applications. Ser. Springer Monographs in Mathematics, Springer Verlag, 2014, xiv + 443 p.

The wide range of his scientific interests (as Fractional Calculus, Special Functions, BVP, Integral Equations, Complex Analysis, Mechanics, Applications) can be seen from the list of his selected publications:

- Reissig, M., Rogosin, S.V., Hübner, F. Analytical and numerical treatment of a complex model for Hele-Shaw moving boundary value problems with kinetic undercooling regularization. Euro. J. Appl. Math. - 1999 Vol. 10 (6) - pp. 561-579.

- Lanza de Cristoforis M., Rogosin S.V. Analyticity of a nonlinear operator associated to the conformal representation in Schauder spaces. An integral equations approach. Math. Nachr. - 2000 - Vol. 220 - pp. 59-77.

- Rogosin S.V. Hele-Shaw moving boundary value problem in a bounded do-main. Local in time solvability. Complex Variables - 2005 - Vol. 50, No 7-11. - pp. 745-764.

- Cattani, C., Doubrovina, O., Rogosin, S., Voskresensky, S.L., Zelianko, E. On the creation of a new diagnostic model for fetal well-being on the base of wavelet analysis of cardiotocograms. Journal of Medical Systems 2006 - Vol. 30 (6) - pp. 489-494.

- Koroleva A., Rogosin S.V. Integral representation of the four-parametric Mittag-Leffler function. Lithuanian Math. J. - 2010 - Vol. 50, No 3 - pp. 337-343.

- Luchko Yu., Mainardi F., Rogosin S. Professor Rudolf Gorenflo and his contribution to fractional calculus. Fract. Calc. Appl. Anal. - 2011 Vol. 14, No 1 - pp. 3-18; DOI: 10.2478/s13540-011-0002-z.

- Rogosin S., Speck F.-O. On the analytical solution of the linearfractional Riemann problem. Math. Nachr. - 2011 - Vol. 284, No 4. pp. 543-559. 
- Kilbas A.A., Koroleva A.A., Rogosin S. Multi-parametric Mittag-Leffler functions and their extension. Fract. Calc. Appl. Anal. - 2013 - Vol. 16, No 2 - pp. 378-404; DOI: 10.2478/s13540-013-0024-9.

- Mishuris G., Rogosin S. An asymptotic method of factorization of a class of matrix functions. Proc. Royal Soc. A - 2014 - Vol. 470, Art. \# 20140109.

- Mainardi F., Rogosin S. George William Scott Blair - the pioneer of fractional calculus in rheology. Comm. in Applied and Industrial Math. 2014 - Vol. 6, No 1 - e481; doi: 10.1685/journal.caim.

- Rogosin, S., Mishuris, G. Constructive methods for factorization of matrix-functions. IMA J. Appl. Math. - 2016. - Vol. 81 (2) - pp. 365-391.

- Rogosin, S., Mishuris, G., Koroleva, A., Vinakurava, A. Analysis of the unilateral contact problem for biphasic cartilage layers with an elliptic contact zone and accounting for tangential displacements. Math. Model. and Anal. - 2016 - Vol. 21, No 5 - pp. 585-609.

- Garrappa R., Rogosin S., Mainardi F. On a generalized three-parameter Wright function of Le Roy type. Fract. Calc. Appl. Anal. - 2017 - Vol. 20, No 5 - pp. 1196-1215; DOI: 10.1515/fca-2017-0063.

- Mishuris, G., Rogosin, S. Regular approximate factorization of a class of matrix-function with an unstable set of partial indices. Proc. Royal Soc. A - 2018 - Vol. 474, Art. \# 20140279; DOI: 10.1098/rspa.2017.0279.

- Rogosin S., Dubatovskaya M. Letnikov vs Marchaud: A survey on two prominent constructions of fractional derivatives. Mathematics - 2018 - Vol. 6 (1), 3; doi:10.3390/math6010003.

See also his Google Scholar profile:

https://scholar.google.it/citations?user=HSrEbX8AAAAJ\&hl=en.

Some more details on the various scientific, organizational and educational activities of jubilee, can be found in an article appearing on occasion of his 60th anniversary at 2008:

- M. Dubatovskaya, A. Koroleva, G. Mishuris, Sergei Rogosin: Achievements so far and further plans. In: V.V. Mityushev, M.V. Ruzhansky (Eds.), Current Trends in Analysis and Its Applications, Ser. Trends in Mathematics, Springer, 2015; pp. 5-7, DOI 10.1007/978-3-319-12577-0_2; file: $9783319125763-c 2 . p d f$.

There are many interesting things standing before Sergei: new plans and events, new scientific ideas, papers and books, next conferences, meetings and contacts, new students and pupils. But we hope that absolute constants are present in his life - love, family, friends and favorite work. And we wish him to so continue ahead.

On behalf of Editorial Board of "FCAA", Virginia Kiryakova, Ed.-in-Chief 


\section{New Books}

Saïd Abbas, Mouffak Benchohra, John R. Graef, Johnny Henderson, Implicit Fractional Differential and Integral Equations (Existence and Stability). De Gruyter Ser. in Nonlinear Analysis and Applications 26, De Gruyter, February 2018, 380 pp., ISBN: 978-3-11055381-9 (eBook), ISBN 978-3-11-055313-0 (Hardcover).

Details: https://www.degruyter.com/view/product/491210.

This book deals with the existence and stability of solutions to initial and boundary value problems for functional differential and integral equations and inclusions involving the Riemann-Liouville, Caputo, and Hadamard fractional derivatives and integrals. A wide variety of topics is covered in a mathematically rigorous manner making this work a valuable source of information for graduate students and researchers working with problems in fractional calculus.

\section{Contents:}

- Preliminary Background; - Nonlinear Implicit Fractional Differential Equations; - Impulsive Nonlinear Implicit Fractional Differential Equations; - Boundary Value Problems for Nonlinear Implicit Fractional Differential Equations; - Boundary Value Problems for Impulsive NIFDE; Integrable Solutions for Implicit Fractional Differential Equations; - Partial Hadamard Fractional Integral Equations and Inclusions; - Stability Results for Partial Hadamard Fractional Integral Equations and Inclusions; - HadamardStieltjes Fractional Integral Equations; - Ulam Stabilities for Random Hadamard Fractional Integral Equations.

The book provides a detailed and mathematically rigorous study of implicit fractional differential and integral equations, with a focus on the existence and stability of solutions.

Of interest to: Researchers and graduate students working in fractional calculus, differential equations, nonlinear analysis, and applications.

Dingyü Xue, Fractional-Order Control Systems (Fundamentals and Numerical Implementations). De Gruyter Ser.: Fractional Calculus in Applied Sciences and Engineering 1, De Gruyter, July 2017, 372 pp., xvi, 175 figs. ISBN: 978-3-11-049797-7 (eBook), ISBN 978-3-11-049999-5 (Hardcover).

Details: https://www.degruyter.com/view/product/476910. 
This book explains the essentials of fractional calculus and demonstrates its application in control system modeling, analysis and design. It presents original research to find high-precision solutions to fractional-order differentiations and differential equations. Numerical algorithms and their implementations are proposed to analyze multivariable fractional-order control systems. Through high-quality MATLAB programs, it provides engineers and applied mathematicians with theoretical and numerical tools to design control systems.

\section{Contents:}

- Foreword, Preface; - Ch. 1: Introduction to fractional calculus and fractional-order control; - Ch. 2: Mathematical prerequisites; - Ch. 3: Definitions and computation algorithms of fractional-order derivatives and integrals; - Ch. 4: Solutions of linear fractional-order differential equations; - Ch. 5: Approximation of fractional-order operators; - Ch. 6: Modelling and analysis of multivariable fractional-order transfer function matrices; - Ch. 7: State space modelling and analysis of linear fractionalorder systems; - Ch. 8: Numerical solutions of nonlinear fractional-order differential equations; - Ch. 9: Fractional-order PID controller design; Ch. 10: Controller Design for multivariable fractional-order systems.

The book: - provides high-precision numerical implementations of fractional calculus aspects; - Explores the applications of multivariable fractional-order control systems; - Addresses every technical point with dedicated MATLAB solutions and illustrations.

Of interest to: Engineers and applied mathematicians, researchers and graduate students working in fractional calculus, control theory, numerical analysis and applications.

Virginia Kiryakova, Institute of Mathematics and Informatics Bulgarian Academy of Sciences, Acad. G. Bontchev Str., Block 8 Sofia1113 - BULGARIA, e-mail: virginia@diogenes.bg

Please cite to this paper as "Ed. Note, FCAA-Volume 21-1-2018", publ. in: Fract. Calc. Appl. Anal., Vol. 21, No 1 (2018), pp. 1-9, DOI: $10.1515 /$ fca-2018-0001 